(c) American Dairy Science Association, 2002.

\title{
Investing in a Robotic Milking System: A Monte Carlo Simulation Analysis
}

\author{
J. Hyde and P. Engel \\ Department of Agricultural Economics and Rural Sociology \\ The Pennsylvania State University \\ University Park, PA 16802
}

\section{ABSTRACT}

This paper uses Monte Carlo simulation methods to estimate the breakeven value for a robotic milking system (RMS) on a dairy farm in the United States. The breakeven value indicates the maximum amount that could be paid for the robots given the costs of alternative milking equipment and other important factors (e.g., milk yields, prices, length of useful life of technologies). The analysis simulates several scenarios under three herd sizes, 60, 120, and 180 cows. The base-case results indicate that the mean breakeven values are $\$ 192,056$, $\$ 374,538$, and $\$ 553,671$ for each of the three progressively larger herd sizes. These must be compared to the per-unit RMS cost (about $\$ 125,000$ to $\$ 150,000$ ) and the cost of any construction or installation of other equipment that accompanies the RMS. Sensitivity analysis shows that each additional dollar spent on milking labor in the parlor increases the breakeven value by $\$ 4.10$ to $\$ 4.30$. Each dollar increase in parlor costs increases the breakeven value by $\$ 0.45$ to $\$ 0.56$. Also, each additional kilogram of initial milk production (under a $2 \times$ system in the parlor) decreases the breakeven by $\$ 9.91$ to $\$ 10.64$. Finally, each additional year of useful life for the RMS increases the per-unit breakeven by about $\$ 16,000$ while increasing the life of the parlor by $1 \mathrm{yr}$ decreases the breakeven value by between $\$ 5,000$ and $\$ 6,000$.

(Key words: robotic milking system, Monte Carlo simulation, capital budgeting, economic analysis)

Abbreviation key: $\mathbf{N B}=$ net benefit, $\mathbf{N P V}=$ net present value, $\mathbf{R M S}=$ robotic milking system.

\section{INTRODUCTION}

The technology of milking cows has changed greatly over time. Farmers who milked cows by hand could handle only a relatively small number of cows. Automa-

Received October 31, 2001.

Accepted April 2, 2002.

Corresponding author: J. Hyde; e-mail: jeffhyde@psu.edu. tion of milking equipment and the use of vacuum pumps made it easier for farmers to milk more cows. Eventually, milking parlors made it possible to milk even more cows in a relatively short period of time. Each of these technological advances decreased the amount of milking labor needed per cow.

In the 1980s, Dutch researchers began to develop robotic milking systems (RMS). The goal was to develop a system that could milk cows with little to no human assistance. By 1992, the first RMS unit was installed for use on a commercial Dutch farm. Since then, many more units have been installed in Europe, where nearly half of all new milking systems installed currently are robotic. Canada and Japan are also witnessing an increasing number of RMS installations.

Farms using one or more robotic units are able to milk cows nearly $24 \mathrm{~h}$ a day, as the cows come through the system voluntarily. Depending upon lactation stage, some cows will be milked three or more times per day, increasing milk production relative to fewer milkings. Empirical observation in Canada suggests that the herd as a whole is milked at a frequency near $3 \times$ (J. Rodenburg, November 2001, personal communication). The RMS also reduces the amount of labor required to milk cows relative to an alternative milking system using a typical $2 \times$ system. The operator may choose to use the resulting excess labor to monitor cow health, clean stalls, or focus on some other activity that will increase farm profits.

There are tradeoffs involved, however. For example, if cows are milked more frequently, they will require increased feed. Also, the robotic units may not last as long as a parlor or other milking equipment. It is important to analyze tradeoffs involved when choosing between the RMS and a milking parlor. It is also important to evaluate the tradeoffs in the context of uncertainty associated with many of the decision factors (e.g., milk price, length of useful life, salvage value). The objective of this research is to estimate the breakeven value of the RMS, representing the maximum economically justified amount that could be paid for the RMS, relative to a milking parlor, given conditions of uncertainty. This breakeven must be compared to the current 
cost of the RMS (about $\$ 125,000$ to $\$ 150,000$ per unit plus any other construction or equipment) to determine if the RMS is a viable alternative. If the breakeven were greater than or equal to cost, then the producer would be better off to purchase the RMS.

Several economic analyses of the RMS technology have been published. One of the earliest papers described a production simulation model with the flexibility to perform several types of analyses (Parsons, 1988). The model was used to match specific herd sizes to a number of robotic units, to determine how the system might operate more efficiently, and to analyze some costs and returns from the system. Because this research was published before the first installation of commercial RMS units, it made some assumptions that may have been inaccurate in light of more recent production-related research [interested readers are encouraged to see Hogeveen and Meijering (2000) for a relatively complete summary of research related to producing milk with an RMS].

Cooper and Parsons $(1998,1999)$ followed with two subsequent papers, again using simulation modeling. In their 1998 paper, they used their model to estimate the number of robots and milking stalls (assuming the potential use of a multi-stall system in which one robot may serve more than one stall) needed for a range of herd sizes. They also incorporated a grazing production system in their consideration of British dairying, where grazing is more common than in the United States.

Cooper and Parsons (1999) used their simulation model to analyze the economic consequences of adopting an RMS. Those results showed that full utilization of the robot's capacity is important. That is, farm profits increased with the number of cows per robot until a critical number of cows per robot were reached. At that point, simulated farm profits fell sharply. They also found that multi-stall units served by one robot appeared to be more profitable than single-stall units. [It is interesting to note, however, that most units in Canada are single-stall ones (J. Rodenburg, July 2001, personal communication)].

A final paper adopted a more thorough economic analysis (Dijkhusen et al., 1997). These authors employed a capital budgeting approach that calculated a breakeven cost of the RMS. This breakeven cost represented the maximum amount that could be paid for the RMS given several input parameters such as the costs of a parlor, labor, feed, and other economic variables. Their results were based on assumptions regarding point estimates for several input variables. They then used sensitivity analysis to determine how robust their estimates were relative to the initial point estimates.

\section{MATERIALS AND METHODS}

This research uses a modified version of the model used by Dijkhusen et al., (1997). Like that work, this investment model uses several specified parameters to estimate a breakeven price for the RMS technology. The breakeven price represents the maximum that the dairy farmer can invest in an RMS given the input parameters and variable distributions. If the cost is above this breakeven price, the farmer would be economically better off to invest in a parlor system at the price specified in the analysis. Our research employs Monte Carlo simulation to estimate a distribution of breakeven prices, rather than a point estimate, as in previous work. This method provides a more robust estimation of the value of the RMS. This section describes the model and data used in the analysis.

\section{Economic Benefits}

The benefits in the model are straightforward to calculate. They consist of all income generated by the milking system (Equation 1).

$$
\begin{aligned}
\text { income }_{i, t}= & \text { cows* }^{*} \text { production }_{i, t} * \text { price }_{i} \\
& + \text { salvage }_{i, t=T}
\end{aligned}
$$

Here, $\mathrm{i}$ indexes milking systems ( $\mathrm{i}=\mathrm{RMS}$ or Parlor); $\mathrm{t}$ indexes time $(\mathrm{t}=1,2, \ldots, \mathrm{T}$; and $\mathrm{T}$ varies between systems); income denotes farm revenues, cows denotes the number of milking cows in the herd; production denotes milk produced per cow per year; price denotes the average mailbox price per $45.4 \mathrm{~kg}$ ( $1 \mathrm{cwt}$ ) of milk over the period of analysis; and salvage represents the salvage value obtained by the producer in the final year of technology i's useful life $(t=T)$. To make a relevant comparison, we assume that the herd size is constant across technologies and time.

Notice that production, price, and salvage are each indexed by i, and thus may vary across technologies. Also, production varies in each period. Here, we assume that production begins at some base level, defined for each specific analysis, and increases each year by a linear trend (production $_{\mathrm{i}, \mathrm{t}+1}=$ production $_{\mathrm{i}, \mathrm{t}}+$ annual production increase). Price is assumed to be constant across the useful life of the technologies. However, price does differ across iterations of the Monte Carlo simulation.

\section{Economic Costs}

Only those costs that differ between milking systems are included in this analysis (Equation 2). Inclusion of other costs would not affect our results and therefore would complicate the analysis. 


$$
\begin{aligned}
\text { cost }_{i, t}=\text { system }_{\mathrm{i}, \mathrm{t}=0} & + \text { labor }_{\mathrm{i}, \mathrm{t}}+\text { feed }_{\mathrm{i}, \mathrm{t}}+\text { tax }_{i, t} \\
& + \text { maint }_{i}
\end{aligned}
$$

Here, cost represents total costs of the milking system; system denotes the investment cost of the milking equipment (realized in year zero; i.e., it is not subject to discounting); labor is the labor costs associated with milking; feed is total feed costs; tax denotes income taxes paid from milking revenues; and maint is maintenance costs. It should be noted that the tax bill is a function of depreciation.

Labor, feed, and tax expenses differ across systems and over time. Thus, they are indexed by both $i$ and $t$. Maintenance costs are assumed to be different for either system but to be constant over their useful lives. Thus, the variable is indexed only by i. Depreciation expenses are based on straight-line depreciation over $7 \mathrm{yr}$ for both systems. This depreciation period was chosen based on the uncertainty inherent in the useful lives of the systems (A. Gentile, February 2002, personal communication).

\section{Net Present Value and Annuity Calculations}

After calculating the economic benefits and costs each year for each system, the costs are deducted from the benefits to obtain net benefits (NB). We then discount the NB using a discount rate of $\delta$ and sum the discounted net benefits over each system's useful life (equation 3). This yields the net present value (NPV) of each system.

$$
\mathrm{NPV}_{i}=\sum_{t=0}^{T}\left[\left(N B_{i, t}\right) /(1+\delta)^{t}\right]
$$

The NPV cannot be used to directly compare the costs and benefits of the alternative milking systems because the systems may have different useful life spans. If each technology lasted for $10 \mathrm{yr}$, for example, the NPV would provide an appropriate measure. However, because the RMS technology is expected to last for fewer years than the milking parlor, it is more appropriate to convert the NPV values to annuities (equation 4).

$$
\operatorname{annuity}_{i}=\mathrm{NPV}_{i}^{*}\left[\delta /\left(1-(1+\delta)^{-T}\right)\right]
$$

The annuity value represents a constant income stream over the useful life of system i, with an NPV equal to that resulting from equation 3 . This conversion allows us to evaluate the annualized income of alternative technologies when they have different useful life spans.

\section{Breakeven Cost of RMS}

Like Dijkhusen et al. (1997), we solve for the breakeven cost after calculating the annuity value for the parlor system. Once the parlor's annuity is known, we simply choose the cost of the RMS technology that will result in the RMS annuity being equal to the parlor annuity. In practice, this task is performed using the "Goal Seek" tool in Microsoft Excel. Obviously, the breakeven value is a function of many of the parameters incorporated into the model. Some important examples include labor costs and the useful life spans of the alternative technologies.

\section{Variables and Parameters}

The model requires several input variables to determine the costs and benefits associated with each milking system. Also, there are some parameters that must be specified. These parameters are constant across all scenarios. Variables and parameters are discussed below and are summarized in Table 1.

Nonstochastic variables. There are four variables for which alternative values are specified across simulations. In each, however, they are nonstochastic. We use these nonstochastic variables to define three base-case scenarios (Table 2).

We analyze three alternative herd sizes; 60,120 , and 180 cows. These are assumed to correspond to one, two, and three RMS units, respectively. These herd sizes are reflective of those analyzed in previous research.

To represent the total cost of building a parlor, we use a range of costs for each herd size (D. McFarland, April 2001, personal communication). These ranges are $\$ 75,000$ to $\$ 150,000, \$ 125,000$ to $\$ 225,000$, and $\$ 200,000$ to $\$ 350,000$ for herd sizes of 60,120 , and 180 cows, respectively. By analyzing how the breakeven value changes over these ranges, we can determine the sensitivity of the breakeven to the parlor cost. We can then compare this across herd sizes. We do this for each of the nonstochastic variables.

For labor costs, we use ranges of $\$ 10,000$ to $\$ 25,000$, $\$ 10,000$ to $\$ 40,000$, and $\$ 20,000$ to $\$ 45,000$ as herd size increases (Rogers, 2001). While these ranges are arguably large, they allow us to better draw conclusions regarding the sensitivity of the RMS breakeven value to the labor cost. Labor costs incurred for other activities are assumed to be the same for both systems, thus not included. We assume that labor costs rise each year, with inflation included as a stochastic variable.

For each herd size, we analyze a range of initial production levels ranging from 6804 to $11,339.9 \mathrm{~kg}$ per cow per year. These assume $2 \times$ milking in the parlor. We assume $3 \times$ milking, on average, in the robot, with a resulting increase in production. This is approximately 
Table 1. Variables used in simulation models.

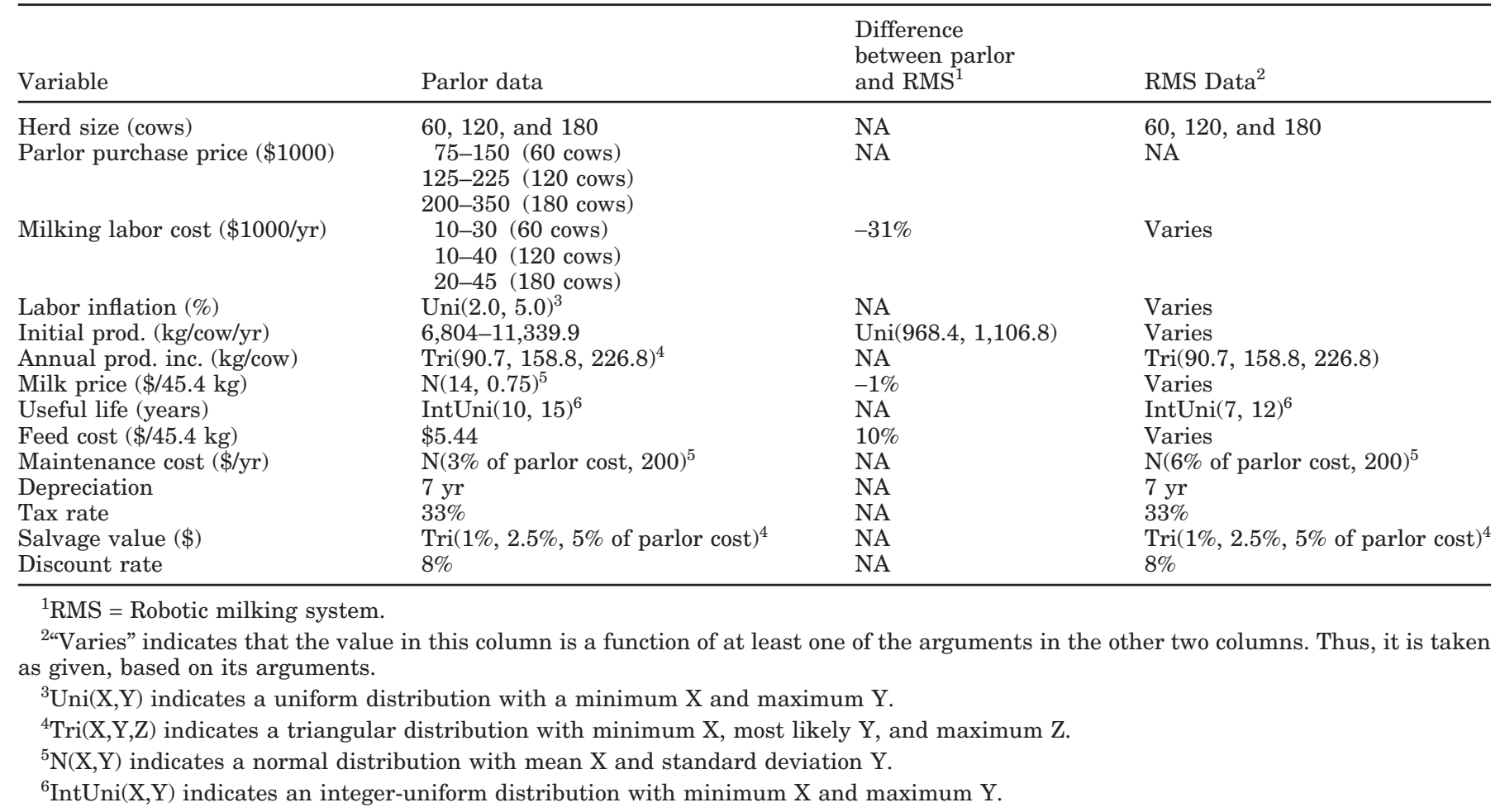

the milking frequency realized on Canadian farms using robots (J. Rodenburg, November 2001, personal communication). It is further assumed that milk production increases each year due to improvements in genetics and production management. These two sources of production increases are stochastic and described below.

Stochastic variables. We specify several stochastic variables, varying in each scenario according to specified distributions.

Two stochastic variables are associated with milk production. First, the increase in production associated with shifting from $2 \times$ to $3 \times$ is distributed as uniform with minimum of $968.4 \mathrm{~kg}$ and maximum of $1106.8 \mathrm{~kg}$ per cow per year (Erdman and Varner, 1995). Furthermore, milk production increases each year. This increase is distributed as triangular with minimum, mode, and maximum of 90.7, 158.8, and $226.8 \mathrm{~kg}$ per cow per year for both milking systems.
For the parlor, milk price is normally distributed with a mean of $\$ 14$ per $45.4 \mathrm{~kg}$ and a standard deviation of $\$ 0.75$. The price received for milk harvested with the RMS is modeled as one percent below the realized parlor price due to lower component levels (Dijkhusen et al., 1997).

The useful life of the parlor is specified as triangular with minimum, mode, and maximum of 10,13 , and 15 yr. The life of the RMS unit(s) is distributed of the same form with arguments of 7, 9, and $12 \mathrm{yr}$. We later analyze the sensitivity of the breakeven values to the useful lives of the two systems. To do so, we set one system's useful life to its modal value and simulate the RMS breakeven values over the range of the other system's useful life. (Therefore, useful life is later treated as a nonstochastic variable in the analysis.)

Labor costs are inflated each year. The inflation rate is distributed as uniform with minimum and maximum of 2 and $5 \%$, respectively.

Table 2. Description of base-case scenarios.

\begin{tabular}{lllll}
\hline Scenario & Herd size & Parlor cost & $\begin{array}{l}\text { Initial production } \\
(\mathrm{kg} / \text { cow/yr })\end{array}$ & $\begin{array}{l}\text { Labor cost for milking } \\
\text { only (\$/year) }\end{array}$ \\
\hline 1 & 60 & $\$ 100,000$ & $8,164.7$ & $\$ 10,000$ \\
2 & 120 & $\$ 175,000$ & $8,164.7$ & $\$ 20,000$ \\
3 & 180 & $\$ 250,000$ & $8,164.7$ & $\$ 30,000$ \\
\hline
\end{tabular}


For the parlor, maintenance cost is assumed to be normally distributed, with a mean equal to $3 \%$ of the cost of the parlor and a standard deviation of $\$ 200$. The maintenance cost for the RMS unit(s) is normally distributed with a mean of twice that of the parlor (or $6 \%$ of the parlor cost) and a standard deviation of $\$ 200$.

Salvage values are distributed as triangular, with minimum, mode, and maximum as given in Table 1. We assumed that the producer could most likely salvage $5 \%$ of the original purchase price of the parlor. However, a capital gains tax of $50 \%$ effectively reduces that to $2.5 \%$. The minimum values are $1 \%$ of the parlor purchase cost, while the maximums are $5 \%$. These are assumed to be the same for both the parlor and the RMS due to a lack of data to specify this relationship more clearly. Because the variance of the salvage values is a function of the parlor cost, changing the parlor cost is one potential source of increased variability in the simulations. This will be discussed further with the results.

Parameters. We assume that both systems are depreciated using a straight-line method over $7 \mathrm{yr}$ (A. Gentile, February 2002, personal communication). A $33 \%$ marginal tax rate is assumed to apply to net farm returns (M. Evanish, April 2001, personal communication). Finally, an $8 \%$ discount rate is assumed for all analyses. This represents a typical alternative return on the capital investment.

\section{Stochastic Simulations}

The main shortcoming of the Dijkhusen et al. (1997) paper is that all of the variables were treated as nonstochastic, with some sensitivity analysis performed to determine the extent to which a change in some of the variables may impact the breakeven value of the RMS technology. However, we specify many of the model's arguments as random variables. Thus, rather than incorporating those as point estimates, we make them stochastic and use Monte Carlo simulation to estimate distributions of breakeven values of alternative scenarios.

The basic capital budgeting model was developed in Microsoft Excel. To perform the Monte Carlo simulation analysis, we used @Risk, an Excel add-in program. @Risk allows the user to specify distributions for any number of input variables. To simulate a single decision, the model makes a single draw from each of the input distributions and combines these with the nonstochastic variables. This set of input parameters generates a unique annuity value for the parlor system. Once this is found, the simulation model initiates a Goal Seek macro to estimate the breakeven value of the RMS
Table 3. Parameters of normal distributions fitted to simulated distributions of breakeven values under base-case scenarios.

\begin{tabular}{lll}
\hline Scenario & Mean & $\begin{array}{l}\text { Standard } \\
\text { deviation }\end{array}$ \\
\hline 1 & $\$ 192,056$ & $\$ 29,452$ \\
2 & $\$ 374,538$ & $\$ 45,573$ \\
3 & $\$ 553,671$ & $\$ 66,968$ \\
\hline
\end{tabular}

technology given that particular set of realized values. This series of events constitutes one model iteration.

Each iteration results in a point estimate for the breakeven RMS value. By including many iterations in a single simulation, we are able to estimate a distribution of breakeven values given the specified set of input distributions and nonstochastic parameters. Once the empirical output distributions are simulated, we use a second software program, to specify the normal distribution that most closely matches the simulated distribution. The results will provide the parameters (mean and standard deviation) of the fitted normal distributions.

\section{RESULTS}

As stated earlier, three base-case scenarios are simulated using different combinations of herd size, parlor price, initial production level, and labor costs (Table 2). All other variables remain as presented in Table 1. For each simulation, 3000 iterations are used. For some iterations, the Goal Seek macro is unable to find a solution. (When this occurs, the resulting breakeven value is greater than one trillion dollars in absolute value.) Consequently, we specify a lower bound on the breakeven value of $\$ 0$ and an upper bound of $\$ 500,000$, $\$ 700,000$, and $\$ 900,000$ for herd sizes of 60,120 , and 180 cows, respectively. Results outside of this range (approximately 15\% of all iterations) are discarded. We then analyze the first 2000 iterations with results falling within the specified bounds. This ensures that the number of iterations analyzed is consistent across all scenarios. Results are presented below in five sections. First, base-case analysis is presented, followed by analysis of sensitivity to labor cost, parlor cost, initial milk production level, and useful lives of the milking systems.

\section{Base-Case Analysis}

The base-case analysis shows that the mean breakeven values are generally greater than the cost of the RMS unit(s) needed to milk that size herd (Table 3). Each unit is approximately $\$ 125,000$ to $\$ 150,000$. (We use this range here as a point of reference only. Prices 


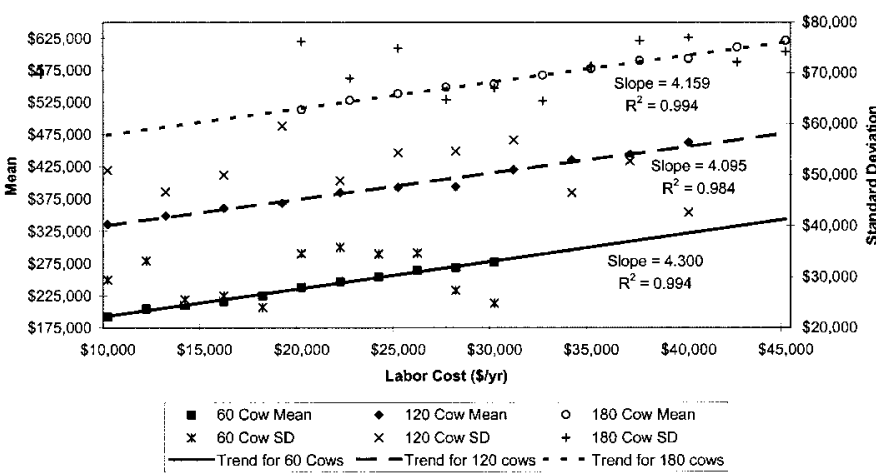

Figure 1. Parameters of normal distributions fitted to simulated distributions of breakeven values to assess sensitivity to labor cost.

of this equipment may vary across manufacturers and over time.) Thus, given the parameter values and variable distributions as specified, a farmer with 60 cows would break even if the full cost of the RMS were $\$ 192,056$. If the full cost of the RMS is less than $\$ 192,056$, then the RMS is a better investment than the parlor. The breakeven value leaves $\$ 67,056$ remaining for any additional construction and equipment (e.g., bulk tank, milk lines, etc.) that may be needed. Likewise, the 120 and 180 cows herds have excesses over RMS unit costs of $\$ 124,538$ and $\$ 178,671$, respectively. All sensitivity analyses described below hold the base-case scenarios constant, changing only the variable of interest.

\section{Sensitivity to Labor Costs}

We vary the labor costs for each herd size over the ranges provided in Table 1 . We then graph the means and standard deviations of the normal distributions fitted to the simulated distribution of breakeven values (Figure 1). It is apparent that the means follow a close relationship, but the variability of the distributions, although differing in magnitude for each herd size, vary only due to the randomness inherent in the Monte Carlo simulations. The slopes of the regression lines fitted to the graphed means are very similar. The slopes range from 4.095 to 4.300 . Thus, each additional dollar in labor savings resulting from adoption of the RMS increases the breakeven value of the RMS by between $\$ 4.10$ (rounded) and $\$ 4.30$.

\section{Sensitivity to Parlor Costs}

We perform a similar analysis of the sensitivity of the breakeven value to the cost of the parlor. The results show that, like those for labor costs, the marginal net value of increasing the cost of the parlor is very similar

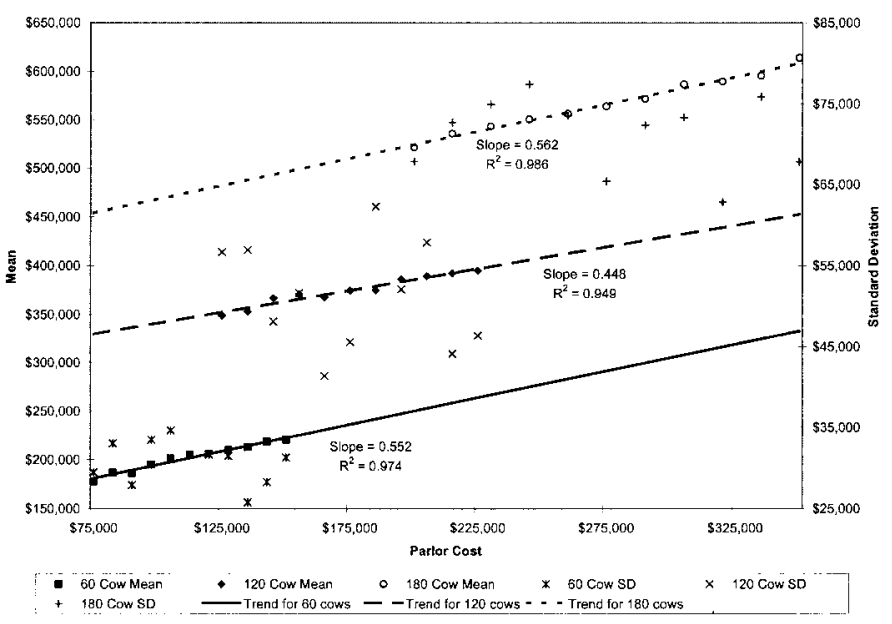

Figure 2. Parameters of normal distributions fitted to simulated distributions of breakeven values to assess sensitivity to parlor cost.

across herd sizes (Figure 2). Specifically, each additional dollar of costs to build the parlor increases the breakeven value of the RMS by between $\$ 0.45$ and $\$ 0.56$ (rounded), as given by the slopes on the fitted regression lines.

\section{Sensitivity to Initial Milk Production}

Results of this sensitivity analysis show that the relationship between herd sizes is different (Figure 3). For the 60-cow herd, each additional kilogram of initial milk production decreases the breakeven cost of the RMS by about $\$ 9.96$, as shown by the slope of the regression line. For the 120- and 180-cow herds, each additional kilogram decreases the breakeven value by $\$ 21.29$ and

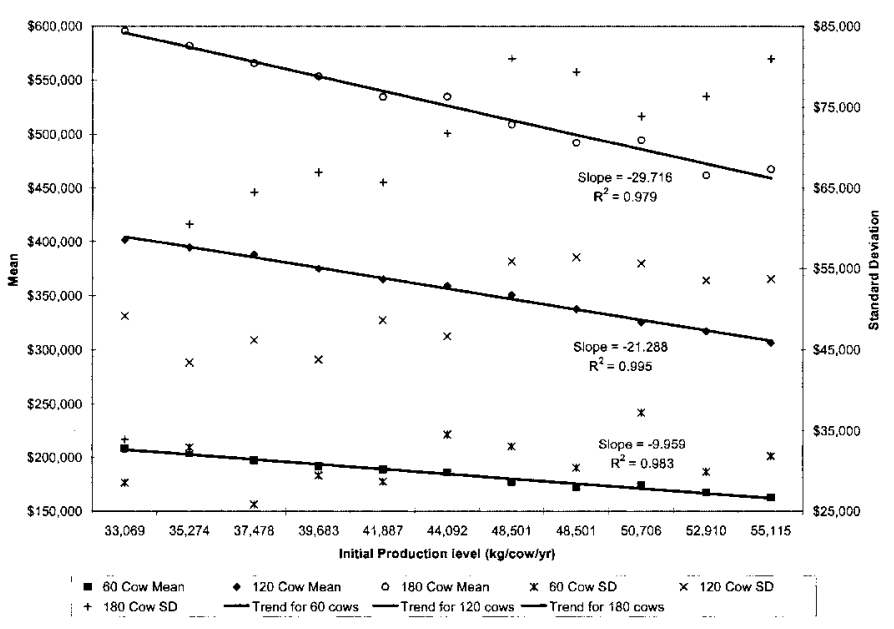

Figure 3. Parameters of normal distributions fitted to simulated distributions of breakeven values to assess sensitivity to initial production level. 


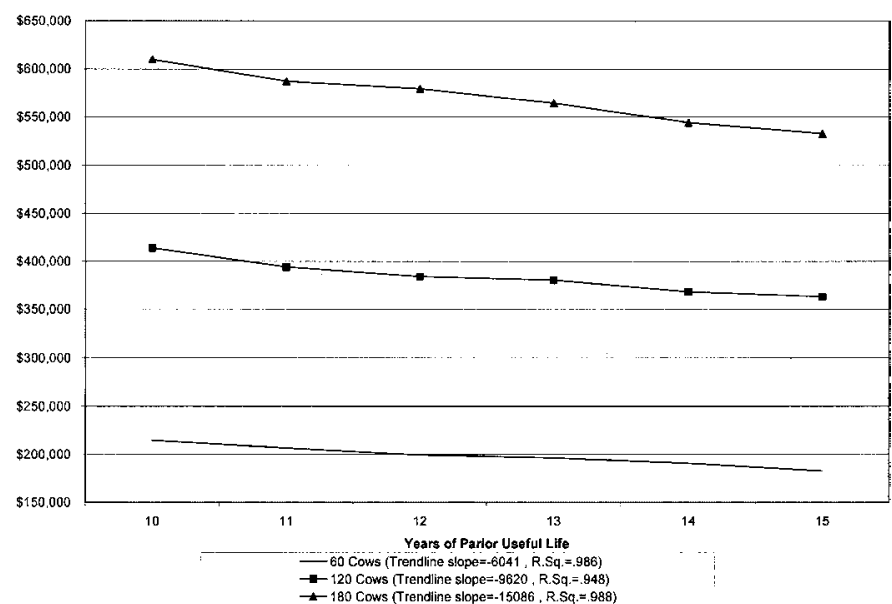

Figure 4. Means of normal distributions fitted to simulated distributions of breakeven values to assess sensitivity to years of useful life of parlor (trendline parameters are given in the legend).

$\$ 29.72$ (rounded), respectively. If we apportion this effect by the number of RMS units needed for that herd size, the effect would be a decrease of $\$ 9.96, \$ 10.65$, and $\$ 9.91$ as herd size increases. Thus, the difference in the slopes is directly attributable to the number of RMS units employed as farm size increases.

The result that the breakeven falls with increases in initial milk production is counterintuitive. It seems more likely that those producers who can achieve high levels of production in the parlor using $2 \times$ milking would be better positioned to benefit from increasing the number of milkings, as is done in the RMS. However, this result arises from our specification of the increases from moving from $2 \times$ to $3 \times$. We model the increased production as being randomly distributed from 968.4 to $1106.8 \mathrm{~kg}$ per cow per year, regardless of initial milk production (Erdman and Varner, 1995). Thus, the marginal benefit of increasing milking frequency is less, in percentage terms, in the higher producing herds. Had we assumed that the benefit was a constant positive percentage of initial milk production, the slopes would have been positive.

\section{Sensitivity to Useful Lives of the RMS and the Parlor}

Finally, we performed sensitivity analysis on the useful life of the two milking systems. We did this by holding one system's useful life constant at its modal value (13 and $9 \mathrm{yr}$ for the parlor and RMS, respectively). We then simulated the breakeven distribution several times, each time increasing the other system's useful life by $1 \mathrm{yr}$, covering the ranges provided in Table 1 . Figures 4 and 5 show the resulting means of the fitted distributions.

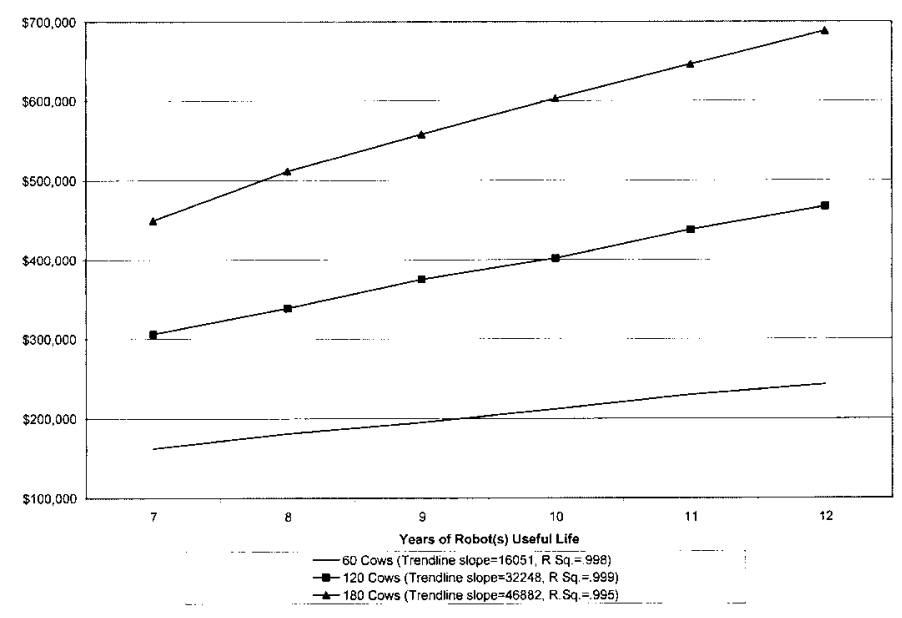

Figure 5. Means of normal distributions fitted to simulated distributions of breakeven values to assess sensitivity to years of useful life of robotic milking system (trendline parameters are given in the legend).

Increasing the length of useful life of the parlor decreases the breakeven value of the RMS (Figure 4). The slopes of the three fitted regression lines show that the effect of each additional year is to decrease the breakeven by $\$ 6,041, \$ 9,620$, and $\$ 15,086$ as herd size increases from 60 to 180 cows. (If we convert this to a per-RMS unit basis, the effect is $\$ 6,041, \$ 4,810$, and $\$ 5,029$.) Thus, the overall effect is less for smaller farms, relative to larger ones, due to a lower number of RMS units.

When the parlor's useful life is held constant and the RMS life is changed, the effect on the breakeven is much more significant than that of the parlor's life. Each additional year of useful life for the RMS increases its breakeven value by $\$ 16,051, \$ 32,248$, and $\$ 46,882$ as herd size increases over the range used here. (This corresponds to $\$ 16,051, \$ 16,124$, and $\$ 15,627$ per RMS unit.) Combined, these results show that, while the length of useful life of the parlor may significantly affect the breakeven value, the length of useful life of the RMS is a much more important consideration. Earlier studies used a useful life of about $7 \mathrm{yr}$ for the RMS (e.g., Dijkhusen et al.). These results suggest that, if producers can realize just one more year of useful life, they will be able to economically justify spending about $\$ 16,000$ more on the RMS, all else constant.

\section{CONCLUSION}

The base-case results presented here suggest that the average breakeven value of the RMS units is above the cost of the units ( $\$ 125,000$ to $\$ 150,000$ each). However, the excess breakeven over the RMS unit costs 
must be enough to pay for construction of facilities, installation of new bulk tank, or other expenses that the farmer must incur to install the RMS. These costs may be significant. In Pennsylvania, for example, it has been mandated that all new units be installed into newly constructed facilities (Dell, January 2002, personal communication). The excess may not be enough to cover these costs, particularly for smaller farms.

Sensitivity analyses showed labor costs, initial milk production, parlor costs, and the useful lives of the two systems may be important factors affecting the breakeven costs, as they differ from the base-case levels. Each additional dollar in labor costs increases the breakeven by approximately $\$ 4.10$ to $\$ 4.30$. Greater initial milk production lowers the breakeven value by approximately $\$ 9.91$ to $\$ 10.64 / \mathrm{kg}$ per unit. Increasing the parlor cost by one dollar increases the breakeven value by between $\$ 0.45$ and $\$ 0.56$. Finally, each additional year of useful life for the RMS increases the per-unit breakeven by about $\$ 16,000$ while increasing the life of the parlor by 1 yr decreases the breakeven value by between $\$ 5,000$ and $\$ 6,000$.

This research does not account for the value of the alternative use of the time saved by adopting an RMS. If the producer is able to use that time to increase farm profits, then the breakeven value of the RMS will increase. For example, some producers might use that time to monitor herd health more closely. Alternatively, that time may be used to perform custom work for a neighboring farm. Regardless, the value of the RMS is a function of the returns that may be generated with this free time. These are not accounted for here because they are expected to be highly variable between farms.

\section{REFERENCES}

Cooper, K., and D. J. Parsons. 1998. A simulation model of an automatic milking system applying different management strategies. J. Agric. Eng. Res. 69:25-33.

Cooper, K., and D. J. Parsons. 1999. An economic analysis of automatic milking using a simulation model. J. Agric. Eng. Res. 73:311-321.

Dell, J. Pennsylvania State Milk Sanitarian. January 2002.

Dijkhusen, A., R. Huirne, S. Harsh, and R. Gardner. 1997. Economics of robot application. Comp. Elec. Agric. 17:111-121.

Dixit, A. K., and R. S. Pindyck. 1994. Investment Under Uncertainty. Princeton University Press, Princeton, NJ.

Erdman, R. A., and M. Varner. 1995. Fixed yield responses to increased milking frequency. J. Dairy Sci. 78:1199-1203.

Hogeveen, H., and A. Meijering, eds. 2000. Robotic Milking. Wageningen Pers, Wageningen, The Netherlands.

Parsons, D. J. 1988. An initial economic assessment of fully automatic milking of dairy cows. J. Agric. Eng. Res. 40:199-214.

Rogers, D. 2001. Milking parlors as a profit center. Pages 3-8 in Milking Systems and Parlors: Planning and Managing for Quality Milk and Profitability. NRAES. Ithaca, NY. 